\title{
ZS Research Square

\section{Study on cement based composite board of wire mesh and straw fibers in severe cold area of Northeast China}

Jie Liu

Qiqihar University

Chun Lv ( Ivchun8603@163.com )

Qiqihar University

\section{Research Article}

Keywords: Cement based materials, wire, rice fibers, composite board, flexural property

Posted Date: January 19th, 2021

DOl: https://doi.org/10.21203/rs.3.rs-145550/v1

License: (c) (i) This work is licensed under a Creative Commons Attribution 4.0 International License.

Read Full License 


\section{Abstract}

There is a large amount of residual straw fibers resources in Northeast China. Rice straw fibers was chosen to make steel-wire-net mortar roof-board composed of straw fibers in different sizes. Cold-drawn and low-carbon steel-wire-nets, whose diameter was $3 \mathrm{~mm}$ and whose size of mesh opening was $60 \mathrm{~mm} \times 60 \mathrm{~mm}$, were set on both upper and lower sides. Vertical tied cold-drawn low-carbon wires were set between the upper and lower cold-drawn and low-carbon steel-wire-lath for spot welding. The distance between two vertical tied steel wires was $120 \mathrm{~mm}$. After the mortar was squirted on the steelwire-nets, outbound alkali resistance fiber glass mesh and thin floated finish make the alkali resistance fiber glass mesh and thin plastering mortar and horizontal wire mesh mortar and compressed straw fibers slab straw fibersboard work together. The deformation characteristics that studies roofboard composed of straw fibers boards; the fracture distribution and the feature of crack developing that studies the boards; the strain distribution and its change law were summarized, the loading mechanism of roof-board composed of straw fibers boards had been studied; by observing the failure form and destruction feature of test specimen, the factors affecting the flexural property of roof-board composed of straw fibers boards had been studied, preparation points of roof-board composed of straw fibers boards had been put forward. The advantages of grass steel-wire-net thin plastering roofboard composed of straw fibers boards reside in cheap materials, moderate carrying capacity and it was easy to be applied.

\section{Introduction}

With the development of northern new rural housing construction, the demand for residential energysaving improves gradually. Residential energy-saving mainly embodies thermal insulation effects of its enclosure construction which includes walls, roofs, doors and windows, etc[1]. The enclosure walls which are now widely used are usually brick-mortar structure composite EPS sheet, or adopt lightweight wood truss, steel frame, straw fibers bale or other lightweight block as filler wall system. Cast-in-place mortar roof board is generally adopted on the roof board, EPS sheet is adopted on the top for heat-retaining properties; there is another type of colored sheet steel composite EPS sheet adopted. The disadvantages of above roof board are relatively larger cost, complex construction patterns and the use that is constrained by local economic condition[2].

A low-cost, energy-conserving, convenient and practical roof board was put forward for bad heat-retaining properties and high-cost of countryside houses in northern and cold areas[3][4][5]. Large amounts of the remaining straw fibers resources were adopted on the roof boards. The roof board was rolled into straw fibers sheet by special straw fibers bale machines. These compact straw fibers sheets were rolled into straw fibers boards and steel-wire-nets were set on the both sides of straw fibers sheets. After the cement mortar was squirted on the steel-wire-nets, outbound alkali resistance fiber glass mesh and thin floated finish make the alkali resistance fiber glass mesh and thin plastering mortar and horizontal wire mesh mortar and compressed straw fibers slab straw fibers board work together. The advantages of grass steel-wire-net thin plastering roof-board composed of straw fibers boards reside in cheap materials, 
moderate carrying capacity and it was easy to be applied. Because of the use of steel-wire-net mortar and alkali resistance fiber glass mesh and thin floated finish, the capability of suffering roof load was high. The straw fibers should be kept dry and it was rain-proof and water-proof in the construction.

Biomass and cement are used in construction projects and many scholars have studied it. Different materials had been studied such as: rape straw fibers and hemp[6], flax shives [7], diss [8], cork [9], sugarcane [10,11], straw fibers bales[12,13], straw fibers-clay[14]. The following experimental investigations were conducted on the roof-board composed of straw fibers boards: test on the mid-span deflection and the deformation characteristics that studies roof-board composed of straw fibers boards; the fracture distribution and the feature of crack developing that studies the boards; the strain distribution and its change law were summarized, the loading mechanism of roof-board composed of straw fibers boards had been studied. By observing the failure form and destruction feature of test specimen, the factors affecting the flexural property of roof-board composed of straw fibers boards had been studied, preparation points of roof-board composed of straw fibers boards had been put forward.

\section{Material Choice}

Rice straw fibers: the soil from its roots and rice head were got rid of fresh and dry rice straw fibers, mildew preventive and insect-resist agents were sprayed to deal with.[15]

Galvanized steel wire bond: the surface was smooth and glabrous, performance function was soft and homogeneous. The diameter of the wire was $1.5 \mathrm{~mm}$.

Cold-drawn and low-carbon steel-wire-nets: the diameter was $3 \mathrm{~mm}$, spot welding was adopted in the making of steel-wire. The size was $60 \mathrm{~mm} \times 60 \mathrm{~mm}$,the intensity strength is $850 \mathrm{~N} / \mathrm{mm}^{2}$.

Mortar: Beijiang P.0 42.5 Portland cement was adopted, natural medium sand from Nenjiang riverbed was adopted for fine aggregate, its fineness modulus was from 2.3 to 2.6 , and its clay content was less than $1 \%$,tap water was adopted for mixing. There were $360 \mathrm{~kg}$ cement, $1450 \mathrm{~kg}$ sand, $275 \mathrm{~kg}$ water per cubic metre in the M20 mortar》 whose consistence was from 50 to $70 \mathrm{~mm}$.

Polymer anti-crack mortar: Beijiang P.0 42.5 Portland cement was adopted as cementitious material, ganister sand was adopted as aggregate whose diameter was from 0.154 to $0.180 \mathrm{~mm}$. Acrylic ester was adopted as polymer.

Alkali resistant glass fibre open weave cloth: the mesh reticulation of open weave cloth should be welldistributed, no visible and outworn run in it.The breaking strength was not less than $750 \mathrm{~N} / 50 \mathrm{~mm}$ in the radial and cyclic direction.

\section{The Preparation Of Roof Board}


straw fibers sandwich layer, steel-wire-net mortar stress layer and alkali resistance fiber glass mesh and thin floated layer were three main parts on the roof board. The length was $900 \mathrm{~mm}$, the width was $420 \mathrm{~mm}$ and the thickness was $200 \mathrm{~mm}$.

\subsection{The preparation of straw fibers sandwich layer}

First, straw fibers sheet should be made by spare, fresh and dry straw fibers. The straw fibers was rolled into straw fibers sheet by special automatic manufacturing facilities for straw fibers mat production. And the length was $900 \mathrm{~mm}$, the width was $420 \mathrm{~mm}$ and the thickness was $30 \mathrm{~mm}$. The straw fibers sheet should be homogeneous and close-grained, it should be soaked in reserve 24 hours in advance. The composite straw fibers sheet adopted reach 5 layers. The thickness was $150 \mathrm{~mm}$. And the straw fibers sheet was held in position tightly by galvanized steel wire bond. The verges of grass mat was going to be cut off in a trimly manner. Finally, the grass mat used for the tests was compressed and processed into straw fibers sandwich layer of roof board.

\subsection{The paving of steel-wire-net}

The roof board and straw fibers sandwich layer have a uniform size. The size was that the length was $900 \mathrm{~mm}$, the width was $420 \mathrm{~mm}$. The thickness of straw fibers sandwich layer was selected upon the requirement of heat-retaining properties. After selecting the straw fibers sandwich layer completed, moistcuring should be done on the surfaces and the surfaces and edges should be cut off in a trimly manner. Cold-drawn and low-carbon steel-wire-nets, whose paving size was $900 \mathrm{~mm} \times 420 \mathrm{~mm}$, were set on both upper and lower sides, vertical tied cold-drawn low-carbon wires were set between the upper and lower cold-drawn and low-carbon steel-wire-lath for spot welding when the surface of straw fibers sandwich layer was dry. The distance between two vertical tied steel wires was $120 \mathrm{~mm}$ and the distance between the upper and lower cold-drawn and low-carbon steel-wire-lath was $200 \mathrm{~mm}$ after welding. After the upper and lower horizontal steel-wire-nets was held in position, spot welding was adopted on the side of straw fibers sandwich layer to seal.

\subsection{The preparation and injection of cement mortar}

After straw fibers sandwich board was supported vertically indoors and held in position tightly, cement mortar was squirted in the preparation of roof board. The cement mortar mix ratio of cement to medium sand was $1: 4.10 \%$ of cement quantity silica fume was added in to ensure the consistency of mortar. The water-cement ratio of mortar was 0.76 .The maximum size of medium sand used was controlled within $5 \mathrm{~mm}$. The Fineness modulus of sand was from 2.3 to 2.6 . The dry materials were stirred by mortar through mortar mixer.

Before mortar was squirted, trial-spraying should be done first. The hydraulic pressure of spray gun and water consumption of mortar should be debugged. The inner pressure of injection machine should be $0.5 \mathrm{Mpa}$. The diameter of dry mixture transportation and tube length should be moderate, the pressure of water- transporting pipes should be stable. The output must be controlled cautiously when squirting. The 
phenomenon of dry-spot and flowing in the squirted mortar should be controlled well. The distance of injection should be controlled to ensure springback amount of sand minimum. The spray angle between spray gun and roof board was controlled under $15^{\circ}$. Mortar should be sprayed homogeneously from top to bottom on the both sides of roof board. Continuous injection was adopted and the injection was controlled at any time to keep regular and homogeneous. The original thickness was controlled about $15 \mathrm{~mm}$, the mortar was packed densely inside the steel-wire-net, and then the thickness of spraying was $15 \mathrm{~mm}$. The thickness of unilateral mortar was about $30 \mathrm{~mm}$. Finishing processing was adopted on the upper side and both sides of the roof board, they should be compacted to level. The abdominal roof board was rolled over to plaster and flatten 24 hours later. Before jet cement mortar protective course initial condensate, wooden float was used to spade and do napping treatment. After initial condensation, plastic membrane was adopted to cover and do curing. The indoor temperature was less than $20^{\circ} \mathrm{C}$ and keep moist 28 days during curing period. The mortar was adopted to make 3 groups of test cube whose size was $100 \times 100 \times 100 \mathrm{~mm}$. The test cube was cured in the same environment conditions with test specimen. The mechanics performance testing of test cube goes on in parallel with experiment on boards.[16]

\subsection{Thin plastering surfacing construction}

The manufacturing process of thin plastering slurry: after addition of water to slurry container, polymer acrylic ester and cement was poured then. The ratio of water to acrylic ester to cement was 1:2:2.The mixture was stirred more 5 minutes by special stirring apparatus to make it homogenize well. Then the mixture was settled more than 5 minutes and was stirred once again, then it will soon be operational.

The outbound alkali resistance fiber glass mesh on the steel-wire-net and the construction of thin floated layer: the thickness of thin floated layer was $2.5 \mathrm{~mm}$, the aggregate size was controlled beyond $1.25 \mathrm{~mm}$. Two adhesive and rendering coat mortar was adopted. First of all, water-proofing and anticracking adhesive and rendering coat mortar whose area exceeds that of fiber glass mesh was applied on the surface of thermal insulating board by steel trowel, the thickness of the mortar was about $1.5 \mathrm{~mm}$. Then fiber glass mesh was pressed into moist adhesive and rendering coat mortar, when it was almost dry, the second adhesive and rendering coat mortar was set to apply. The thickness of the adhesive and rendering coat mortar was subject to covering fiber glass mesh, it was about $1 \mathrm{~mm}$ and total thickness was about $2.5 \mathrm{~mm}$. Water-proofing and anti-cracking layer was just smoothed down, collecting and press finishing was no need to done. The smooth degree of finishing layer was controlled about $\pm 4 \mathrm{~mm}$. After the construction of finishing layer was completed, it should be cured 28 days.

The bending side of the gridding cloth should be put inside in the paving of the gridding cloth. The gridding cloth should be smoothed down from the middle to the upper, the lower, the left and the right to make it cling to the bottom slurry mixture by the float. The gridding cloth overlap and the lap length from the upper to the lower was not less than $100 \mathrm{~mm}$,the lap length from the left to the right was not less than $80 \mathrm{~mm}$. The gridding cloth should not be folded, hollowed, warped and exposed[17]. The gridding cloth in the corner of the roof board should overlap and be buried duplex angle from both sides and the lap length 
was not less than $200 \mathrm{~mm}$. The performance index of ordinary alkali resistance fiber glass mesh was shown Tab.1.

Tab. 1 The performance index of ordinary alkali resistance fiber glass mesh

\begin{tabular}{ccc}
\hline Items & Unit & Index \\
\hline Center distance of mesh & $\mathrm{mm}$ & $4 \times 4$ \\
Weight of unit area & $\mathrm{g} / \mathrm{m}^{2}$ & $\geq 145$ \\
$\begin{array}{c}\text { Breaking strength } \\
\mathrm{N} / 50 \mathrm{~mm}\end{array}$ & $\geq 750$
\end{tabular}

Alkali breaking strength retention

$\% \quad \geq 50$

Din the radial and cyclic direction!

Elongation at break

Din the radial and cyclic direction $\square$

$\% \quad \leq 5$

The roof board completed was shown Fig. 1 and Fig. 2, the length was $900 \mathrm{~mm}$, the width was $420 \mathrm{~mm}$, the thickness was $200 \mathrm{~mm}$. The thickness of mortar was $30 \mathrm{~mm}$ on the upper layer of board, $15 \mathrm{~mm}$ on the lower layer of board. Alkali resistance fiber glass mesh and thin floated finish was adopted, the thickness of thin float on the upper and lower sides of roof board was $15 \mathrm{~mm}$. As shown in Fig. 1 and Fig. 2. 1 was the vertical steel wire, 2 was the steel wire mesh, 3 was the M20 mortar.

The required materials and equipment: static resistance strain gauges, strain gauge, multimeter, terminal, wire, adhesive, acetone, absorbent cotton, sandpaper, tape, toolbox, experimental component, vernier calipers, measuring tape, pencils, YJ-L-700 structure mechanics combined experimental device, per table, static resistance strain gauge.

Dial: used for measuring bearing and deflection

Static resistance strain gage: for measurement of strain of mortar

Use the briquette to test the pressure, at the same time, proceed the mechanics performance testing of the briquette and experiment of the slab.( The briquette was the M20 mortar)

Measure and record the actual size of the slab. Weight; $80.36 \mathrm{~kg}$. Paste 5 groups of mortar strain gauges on the mid-span of top surface of the roof, and lead wires out according to the strain gauge position from top to bottom number (Fig. 3). Install the test plate into right place, and arrange the distribution of beam, jack and reactor in proper order as shown below. Connect the wires of the strain and the wires of 
temperature compensating plate to the static resistance strain gauge, and ensure each line was pathway by using an ohmmeter to measure resistance.

\section{Materials And Test Process}

\subsection{Test preparation}

The required materials and equipment: static resistance strain gauges, strain gauge, multimeter, terminal, wire, adhesive, acetone, absorbent cotton, sandpaper, tape, toolbox, experimental component, vernier calipers, measuring tape, pencils, YJ-L-700 structure mechanics combined experimental device, per table, static resistance strain gauge.

Dial: used for measuring bearing and deflection

Static resistance strain gage: for measurement of strain of mortar

Use the briquette to test the pressure, at the same time, proceed the mechanics performance testing of the briquette and experiment of the slab.( The briquette was the M20 mortar)

Measure and record the actual size of the slab. Weight; $80.36 \mathrm{~kg}$. Paste 5 groups of mortar strain gauges on the mid-span of top surface of the roof, and lead wires out according to the strain gauge position from top to bottom number (Fig. 3). Install the test plate into right place, and arrange the distribution of beam, jack and reactor in proper order as shown below. Connect the wires of the strain and the wires of temperature compensating plate to the static resistance strain gauge, and ensure each line was pathway by using an ohmmeter to measure resistance.

\subsection{Designing of test-piece loading}

The specimen adopt simple form with both ends placed at the rolling hinged support. The distributive girder divides the single beam distribution concentrated load into two equal concentrated load. With the synchronous hydraulic jack forward load was applied to the pressure sensor, and the strain gauge control by graded loading method, measuring and recording the crack width by reading microscope. Supports and cross the position indicator. On both sides of the layer below the surface were respectively pasted strain gauges to measure strain (Fig. 4 and Fig. 5).

\subsection{Experiment process}

The main parameters of this experiment include the external force (counter force of the support, the external load), the internal force and deformation of the (mainly refers to the deflection and cracks, and the relevant measuring instruments comprise a load sensor, resistance strain gauge, displacement meter and reading microscope. Strain measurement uses resistance strain gauge, which was based on the Wheatstone bridge. The Wheatstone bridge measures the output voltage of the resistance strain gauge in 
order to get the strain rate. Measurements of force utilize strain rate caused by the sensibility of sensor to transform it into resistance. Then you should connect the strain gage and the bridge circuit. Therefore, the output change of the bridge was proportional to the change of the measured force. The measurement of the crack utilizes the reading microscope.

Deflection measurement: According to the shape of the floor, we can carry out the test according to the support and loading condition of the simply supported beam. The deflection value of the plate was one of the most comprehensive properties of the measured data. Among them, the most important was to measure the maximum deflection value. In order to obtain the true deflection, the settlement must be considered. If the deflection in the span was measured relative to the ground, it was necessary to determine the settlement value of the same ground at both ends of the beam. So three measuring points were chosen, both ends of the support and cross layout.

Strain measurement: In the test to measure the strain caused by bending, usually layout of measuring point mutation in the plate under positive and negative bending moment section or the largest bending moment on the cross section. In the cross section of paste 5 strain gauges, such as map layout.

Measurement of crack:We often need to determine the anti-cracking performance of the reinforced mortar plate in the experiment. The general vertical cracks take place in maximum tension section, so we need set the continuous observation points in this section section.

The steps of the experiment include the following aspects:

Install the test pieces, install the instruments and debug by linking parallel line.Read dial gauge and strain gauge before loading, use a magnifying glass to check and record the initial crack.In order to determine the strain distribution along the height of the load, you should load the first stage of the estimated cracking load and read the strain gauge carefully under each load.

In the second load you should carefully observe whether there was a crack in the beam tension zone, and at any time write down the load.

Every time read indicator after loading five minutes to determine the displacement and bearing value of the mid-span.

Cracking load to load the secondary loading, read dial gauge and strain gauge after the load was added to a standard 15 minutes, and read measured maximum crack width by reading a magnifying glass.

\section{Data Analysis}

According to the actual stress situation of the house panel, the two ends of the roof-board were loaded with the rolling hinge support, and the distribution of the beam will be divided into two equivalent concentrated loads. Using the synchronous hydraulic jack positive load, the experiment was a total of 256 times, once every $5 \mathrm{~S}$ sampling, loading range of 0 to $38.25 \mathrm{kN}$. The experimental results and the 
drawing of the upper load strain curve shows that it was divided into three stages: elastic working state, cracking state and failure. The carrying capacity meets the requirements of engineering application.

\subsection{Flexible working state}

When the load was started, the bending moment was very small, so the strain of each fiber along the plate was very small. Because the strain was very small and the mortar was basically in the elastic working stage, the stress was proportional to the strain. At this time, the plate was in the small deflection, the growth of deflection has a linear relation with the increasing of the load, the mortar in the compression zone shall force graph was a straight line, the tension zone of mortar was linear with stress diagrams in the early stage and the late curve, load deflection curve was essentially linear relationship.

\subsection{Cracking stage}

When the specimens reaches to the cracking moment, there was the first crack in a the section of the weakest tensile ability. Crack plate works from the first stage into the second stage. Also in the cracking section, due to the tensile zone of mortar cracking was out of work, the original assuming that part of the tension suddenly passed to the longitudinal tensile reinforcement, causing that the longitudinal tensile reinforcement stress increases suddenly, and continued to increase with the bending moment of the original cracks increased and extended upward.As shown in Fig.6.

\subsection{Failure stage}

At this stage, the stress capacity of the roof-board changes a lot on account of the steel reaching the yield strength, while the stiffness of time decreases rapidly and deflection increases sharply, but the mortar compression stress level was still very low. The section of the pulled steel wire break down with reaching the limit tensile strain. Loading deflection curve was close to the level of the curve.As shown in Fig. 7.

The relationship curves of load and strain during the loading process were shown in Figure 8 to fig. 11 . Fig. 8 and Fig. 9: the relationship between load and deformation of the plate. From fig. 8 and Fig. 9, we can see that when loading to $5 \mathrm{KN}$, the deformation of the plate was very small, and the plate was in elastic state, which belongs to the first stage. When the load was greater than $5 \mathrm{KN}$, in the mid span deformation began to increase, and board capacity growth was not obvious. The plate into the second stage, namely crack. When loaded to $10 \mathrm{KN}$ above, in mid span deformation began to increase, and the bearing capacity of the bearing capacity to stop growth. The plate into the third stage, namely the failure state. Fig. 10 and Fig. 11 for the upper part of the plate load and strain curve. From Fig.10 and Fig. 11 can be seen in the upper part of the strain variation was small when loaded to after unfolding while falling from left to right, indicating that the plate in the elastic state, belongs to the first stage; when loaded to $7 \mathrm{KN}$ to $10 \mathrm{kN}$. In the upper part of the strain changes began to increase, and carrying capacity was also synchronous growth, that beam into the second stage, including cracking state; when loading to $10 \mathrm{kN}$ above, in rapid changes in upper strain while the bearing capacity bearing ability to stop growth. The board enters the third stage, that was, the destruction of the state. 


\section{4 suggestions of engineering application}

Changing according to local conditions is accessible. Being filled with other crop straw fibers can also keep warm, but we must pay attention to moisture protection work.

Properly increase the strength of mortar. Increase the bearing capacity of the roof-board to a certain extent.

\section{Conclusion}

House panel shoulders the load mainly through an upper and a lower wire mesh and cold drawn low carbon wire mesh insert provided with a vertical tie of cold drawn low carbon wire, and through the action of cement mortar. Experiments show that the thickness of cement mortar and the number and direction of transverse steel wire mesh have an effect on loading capacity. [18][19][20] The plastering layer of thin roof board majors in anti-water and anti-impact. In addition, it should have smaller water vapor permeation resistance. Wiping the surface layer of the middle alkali mesh can make anti cracking protective layer deformation stress to the surrounding uniform dispersion, both limit along the direction of the alkali resistant mesh deformation and the alkali Mesh in a vertical direction maximum deformation. In order to better stand the roof plate end of the shear, the end of the vertical steel wire should be properly encrypted.

Experiments show that load has a approximate linear relationship with deflection in the roof-board before its cracking. When the first cracking appears, the curve of the transition of roof-board has a larger displacement. Due to the protection of wire mesh, roof-board still has a certain strength. But when the load reaches the yield strength of wire mesh, deflection increases rapidly, the bearing capacity of the roofboard decreases rapidly. straw fibers sandwich layer through the barbed wire, cement mortar and alkali resistant mesh thin plaster finishes as bear part of the load of the roof, reached its as a result of the loadbearing roof-board. Wire mesh thin plastering of rice straw fibers composite roof-board with good insulation performance, moderate load-bearing effect, and through the side and the lower side of the surface of the cement mortar and alkali resistant mesh thin plaster finish, raise the roof-board durability and fireproof performance, low price of the material, construction process simple. The straw fibers house panel is suitable for the low level ecological structure house,[21] and is especially suitable for the construction of the rural energy saving residence in the cold area.

\section{References}

[1] Libo Luo. Ferrocement application on shear strengthening of reinforced concrete beam , concrete, 2013, 285 (7), pp. 141-143.

[2] Lv Chun, Xiao bin Zhao, Daoming Zhang etc.. Cold grass brick composite steel wire net self loadbearing and energy saving wall, Concrete and cement products, 2014, (04), pp. 78-80. 
[3] S. P. Raut, S. A. Mandavgane, R. V. Ralegaonkar Application of small-scale experimental models for thermal comfort assessment of sustainable building materials International Journal of Civil Engineering, 2014, Vol. 12, No. 4,pp. 439-446.

[4] V.V. Sakhare, S.P. Raut, S.A. Mandavgane, etc. Development of sustainable retrofitting material for energy conservation of existing buildings, International Journal of Civil Engineering, 2015, Vol. 13, No. 4A, pp. 411-418.

[5] H. Famili, M. Khodadad Saryazdi, T. Parhizkar. Internal curing of high strength self consolidating concrete by saturated lightweight aggregate - effects on material properties, International Journal of Civil Engineering, 2012, Vol. 10, No. 3, pp. 210-221.

[6] M. Rahim , O. Douzane, A.D. Tran Le, G. Promis, T. Langlet, Characterization and comparison of hygric properties of rape straw fibers concrete and hemp concrete, Construction and Building Materials, 102 (2016), pp. 679-687.

[7] M.Rahim, O.Douzane, A.TranLe, etc., Characterization of flax lime and hemp lime concretes: hygric Properties and moisture buffer capacity, Energy Build. 88(2015), pp. 91-99.

[8] M. Sellami, M. Merzoud, S. Amziane, Improvement of mechanical properties of Green concrete by treatment of the vegetals fibers, Constr. Build. Mater. 47(2013), pp. 1117-1124.

[9] S.Silva, M. Sabino, E. Fernandas, etc., properties, Capabilities and applications, Int. Mater. Rev. 50(6) (2005), pp.345-365.

[10]Z.Kodah, M.Jarrah, N.Shanshal, Thermal characterization of foam-cane as an insulant material, Energy Convers. Manage. 40(4)(1999), pp.349-367.

[11]K. Manohar, J. Ramroopsingh, D. Yarbrough, Use of sugarcane fiber as building insulation, Am. Soc. Test. Mater. 1426(2002), pp. 299-313.

[12]T. Ashour, H. Georg, W. Wu, Performance of straw fibers bale wall: a case of study, Energy Build. 43(8) (2011), pp. 1960-1967.

[13]S. Goodhew, J. Carfrae, P. DeWilde, Briefing: challenges related to straw fibers bale construction, Proc. Inst. CivilEng.: Eng. Sustain. 163(4)(2010), pp. 185-189.

[14]D. Alejandro, Energy and carbon embodied in straw fibers and clay wall blocks Produced locally in the Andean Patagonia, Energy Build. 70(2014), pp. 15-22.

[16] Yang Jingjing, Yang Liu, Xilong Zhang. Application of grass brick wall structure system of , architecture technology, 2015, 46 (11), pp. 1024-1026. 
[17]Gaojuan.Concrete sandwich plate bending test research and finite element analysis,. Ji'nan :University of Jinan, 2007.5.

[18] Xie Jian, Limin Zhu, Ziqiang Dai.concrete sandwich panels - sandwich plate theory analysis and finite element analysis, China Civil Engineering Journal, 2005, 38 (7), pp. 39-44.

[19] Wang Xin, Wang Qin, Li Ying. A new type floor and wall pile load test on , Journal of Shandong Jianzhu University, 2010, 25 (3), pp. 290-292.

[20] Li Yisong. light composite roof-board (floor) of the strength and deformation of the performance of , Tianjin: Tianjin University, 2003.6.

[21] Huang Wei, Wang Dongdong, Zhang Chenghua. The performance comparison of different ecological composite wall material mechanics analysis of, Industrial construction, 2014, 44 (2), pp. 74-79.

\section{Figures}

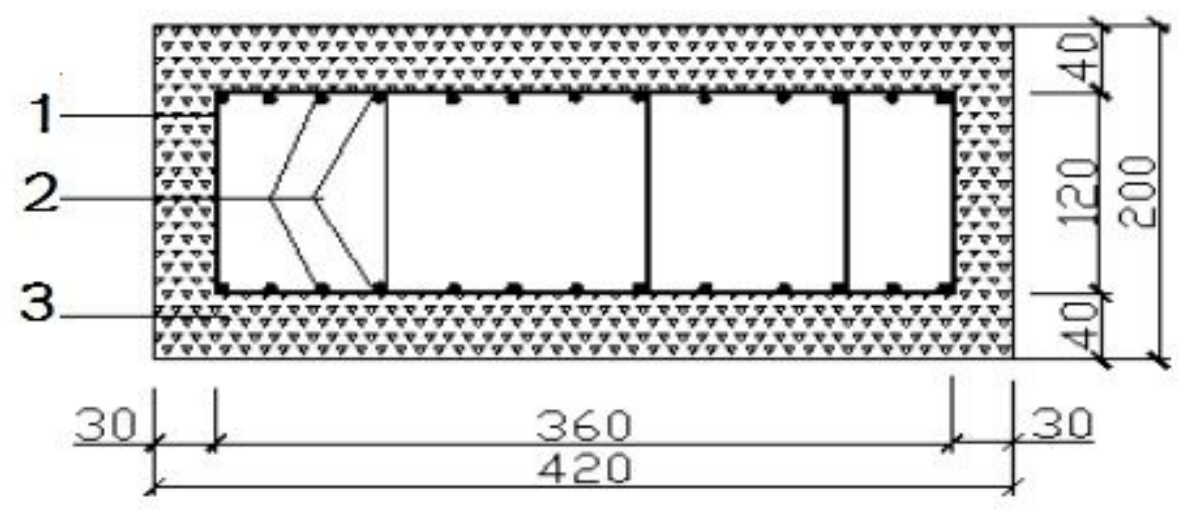

Figure 1

Plate cross section

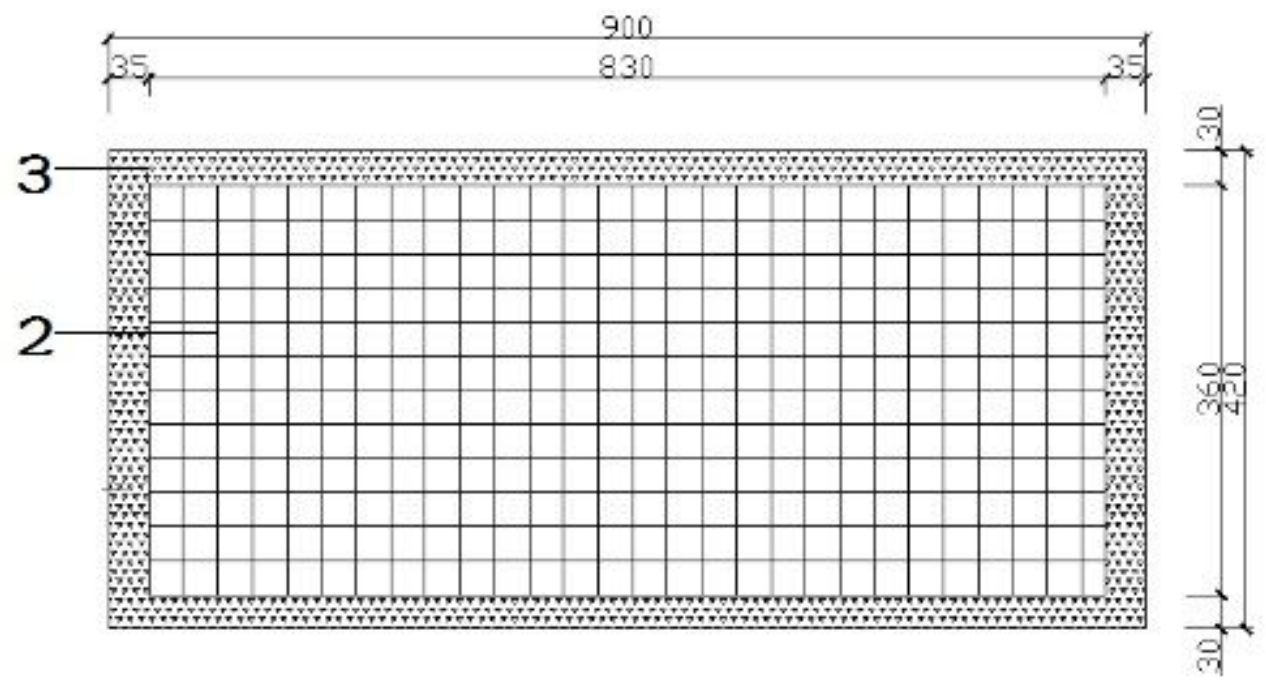


Figure 2

\section{Plate plan}

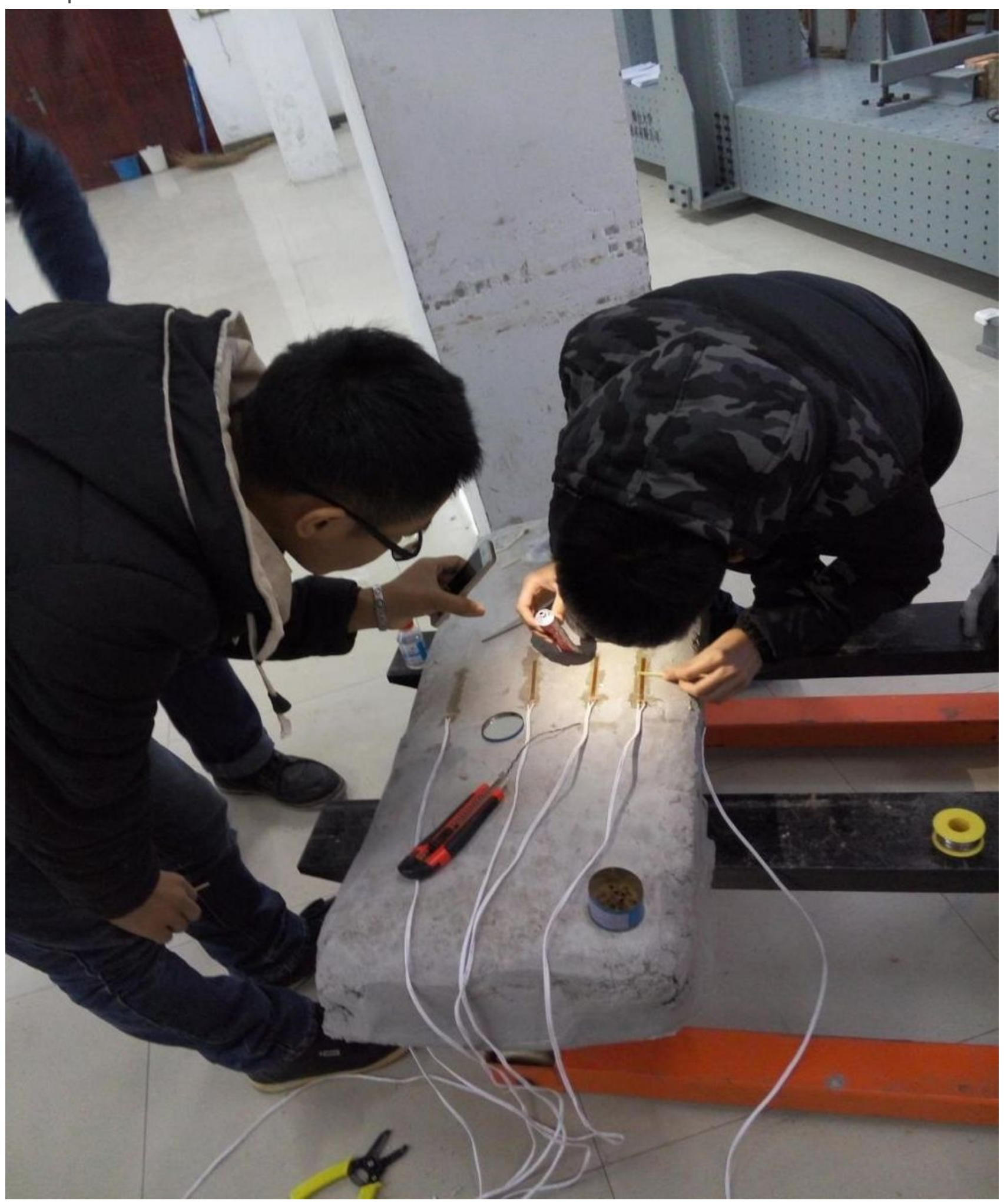

Figure 3

mortar strain gauge 


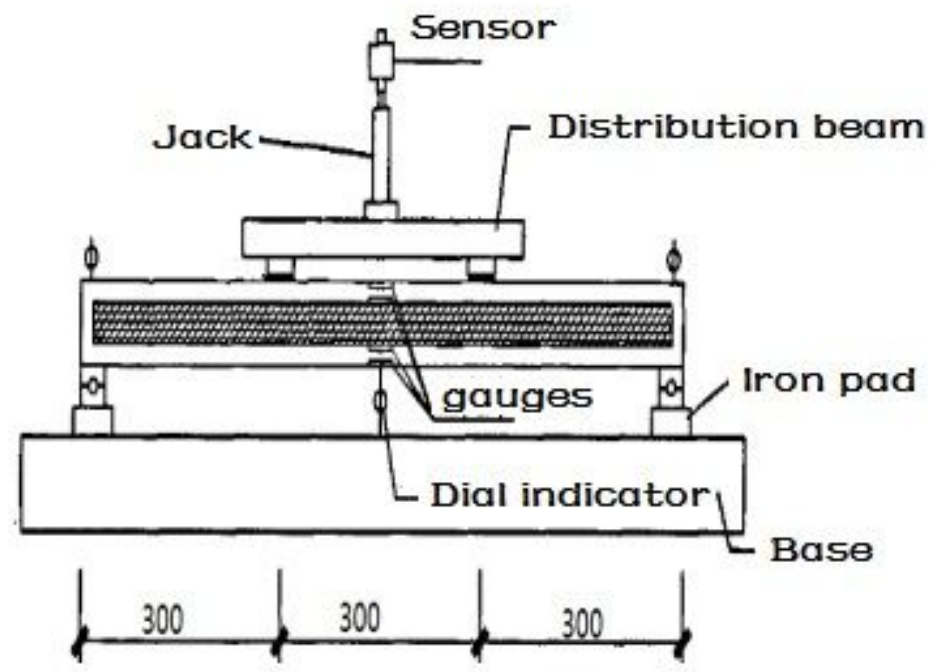

Figure 4

Sketch of specimen loading

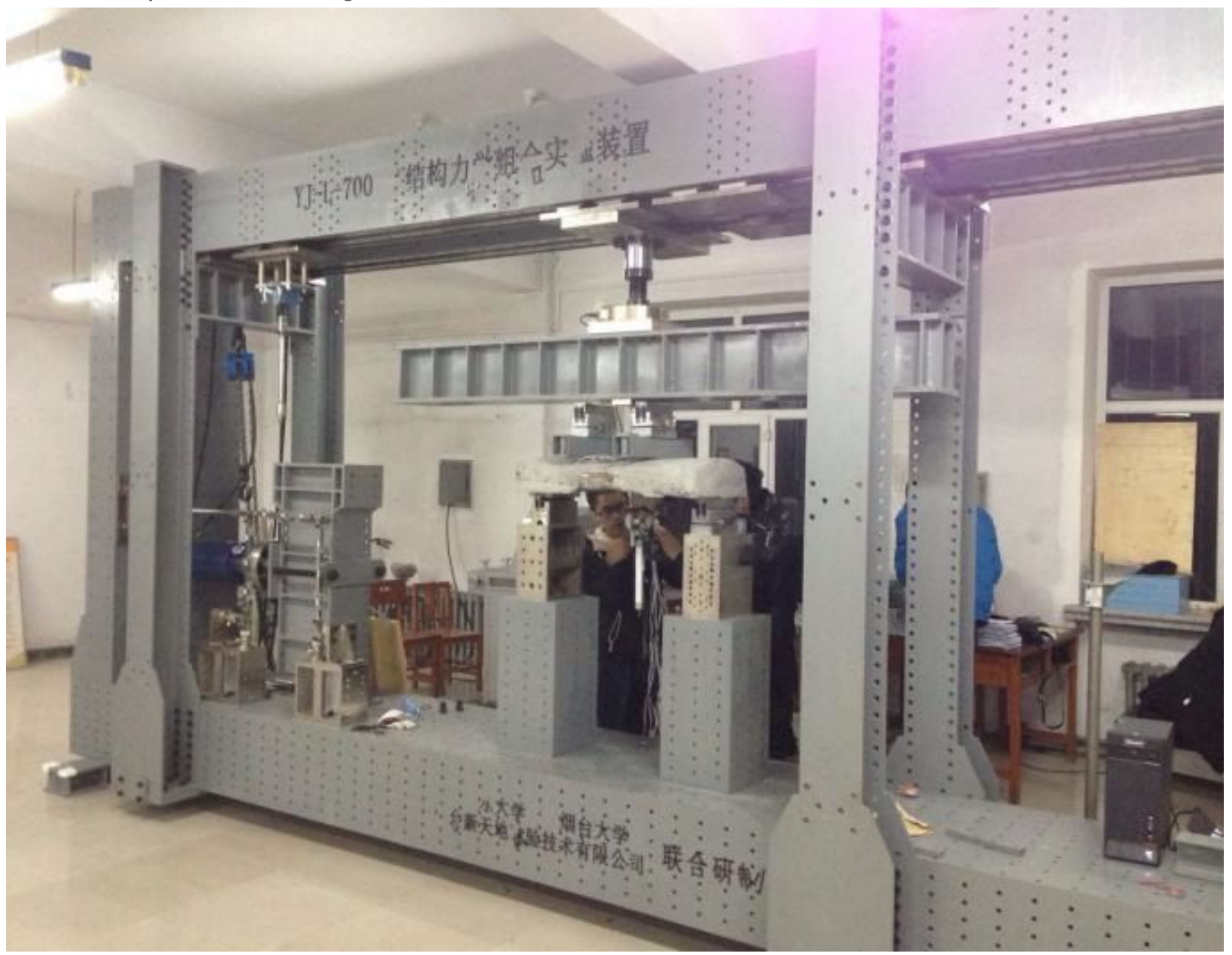

Figure 5 
Specimen loading site

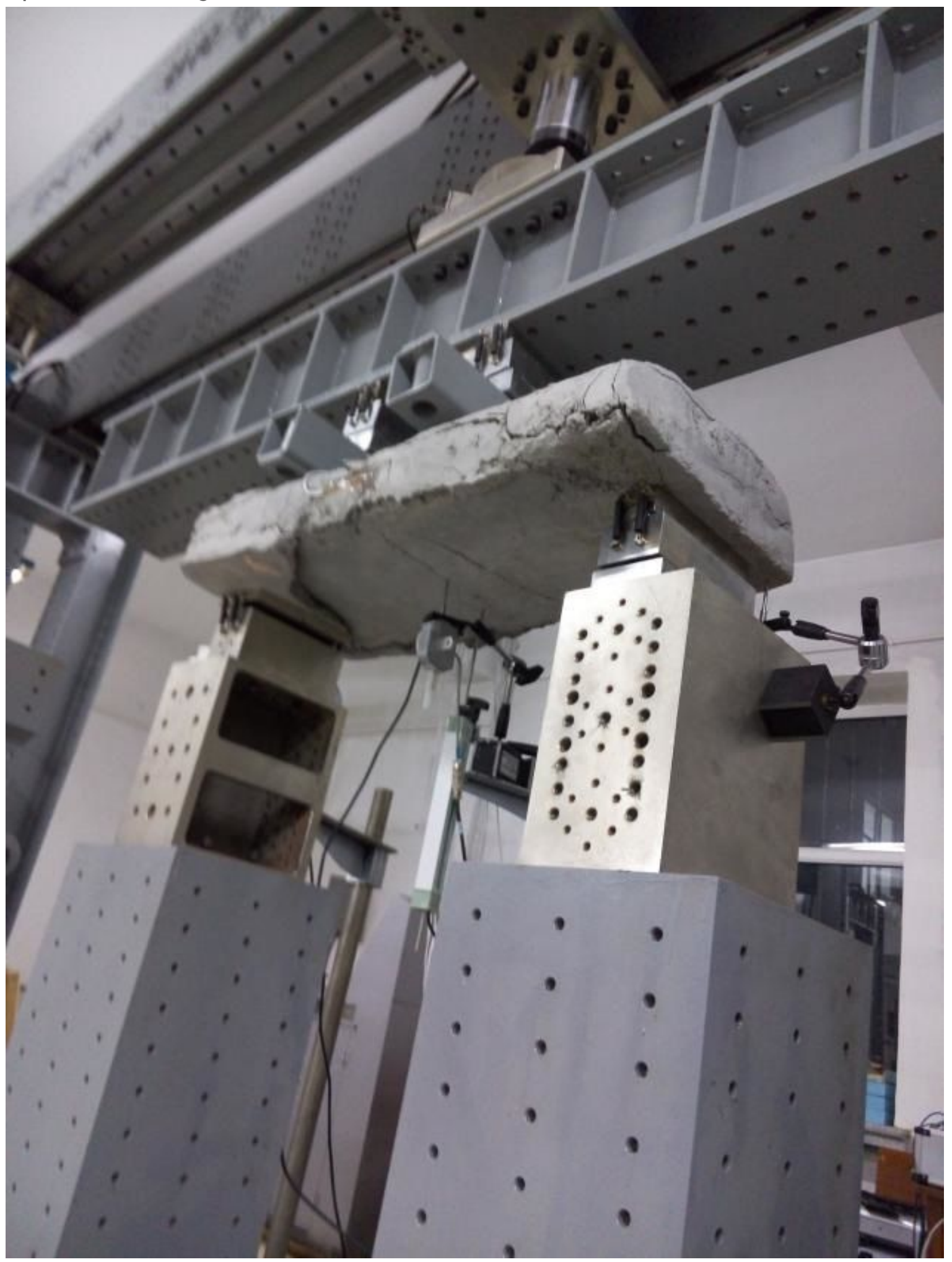

Figure 6

cracking stage 


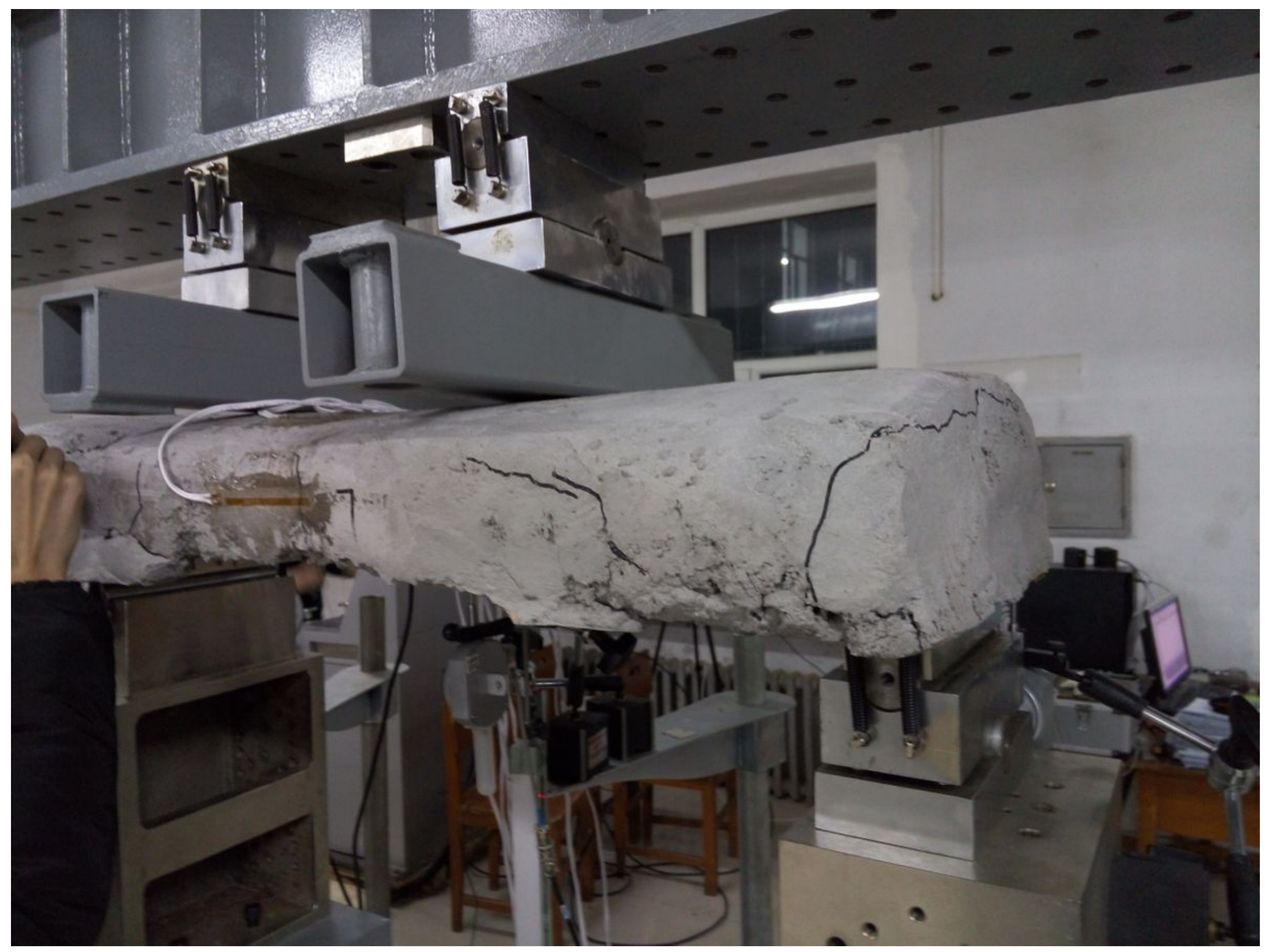

Figure 7

failure stage

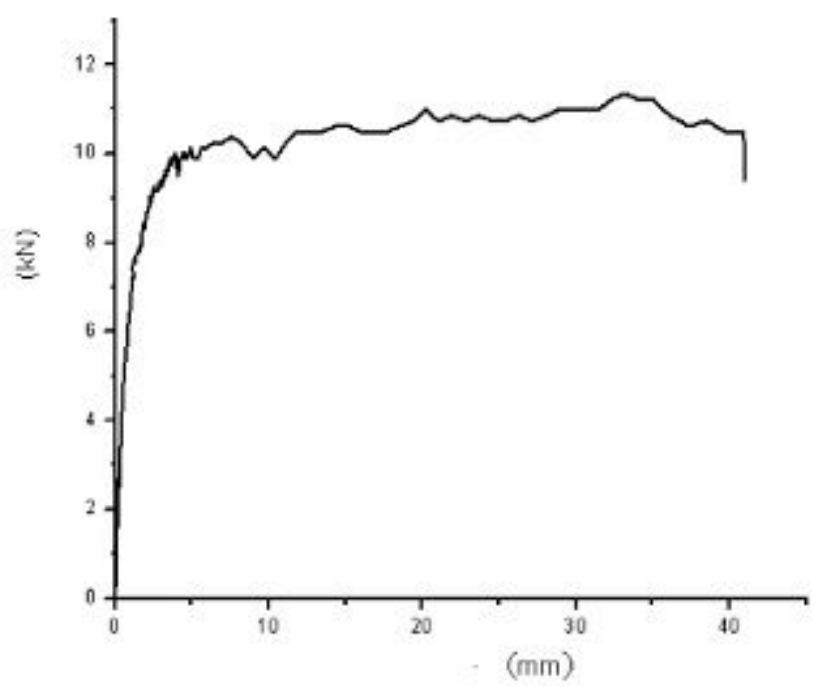


Figure 8

Curves 1 of load and displacement

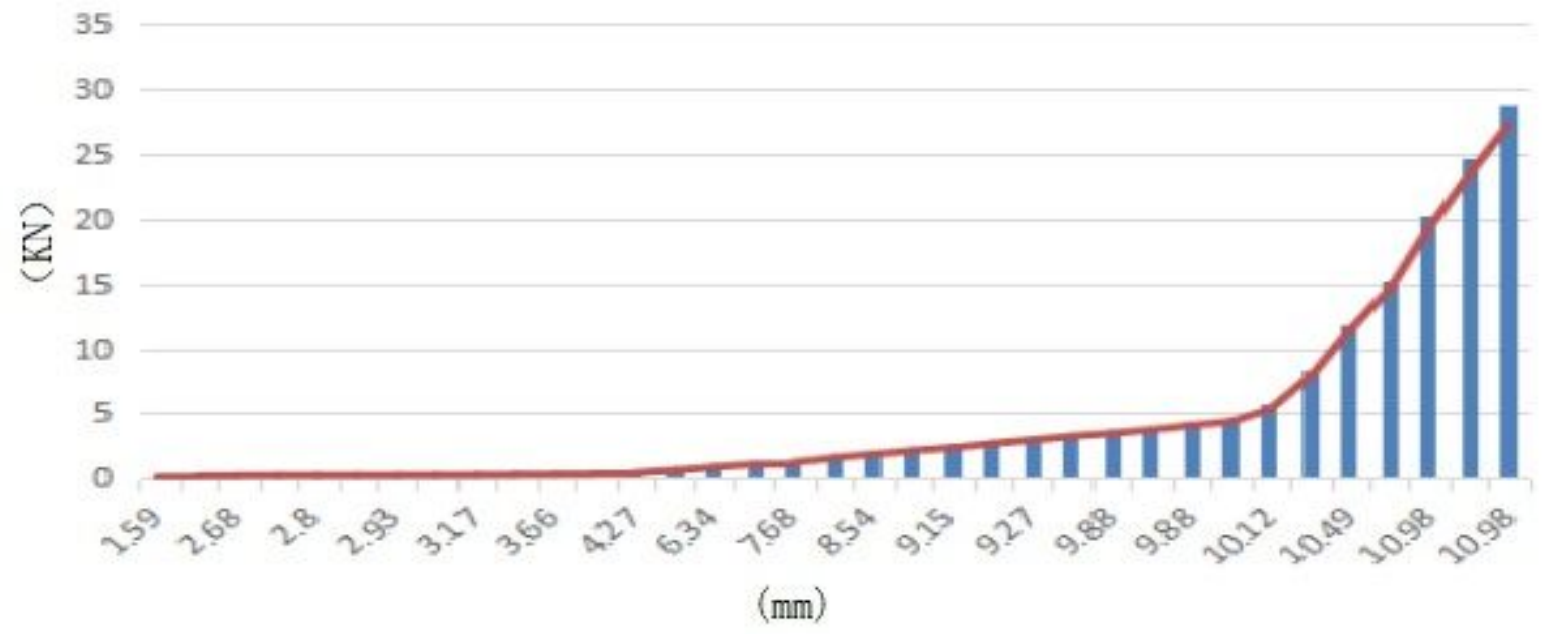

Figure 9

Curves 2 of load and displacement

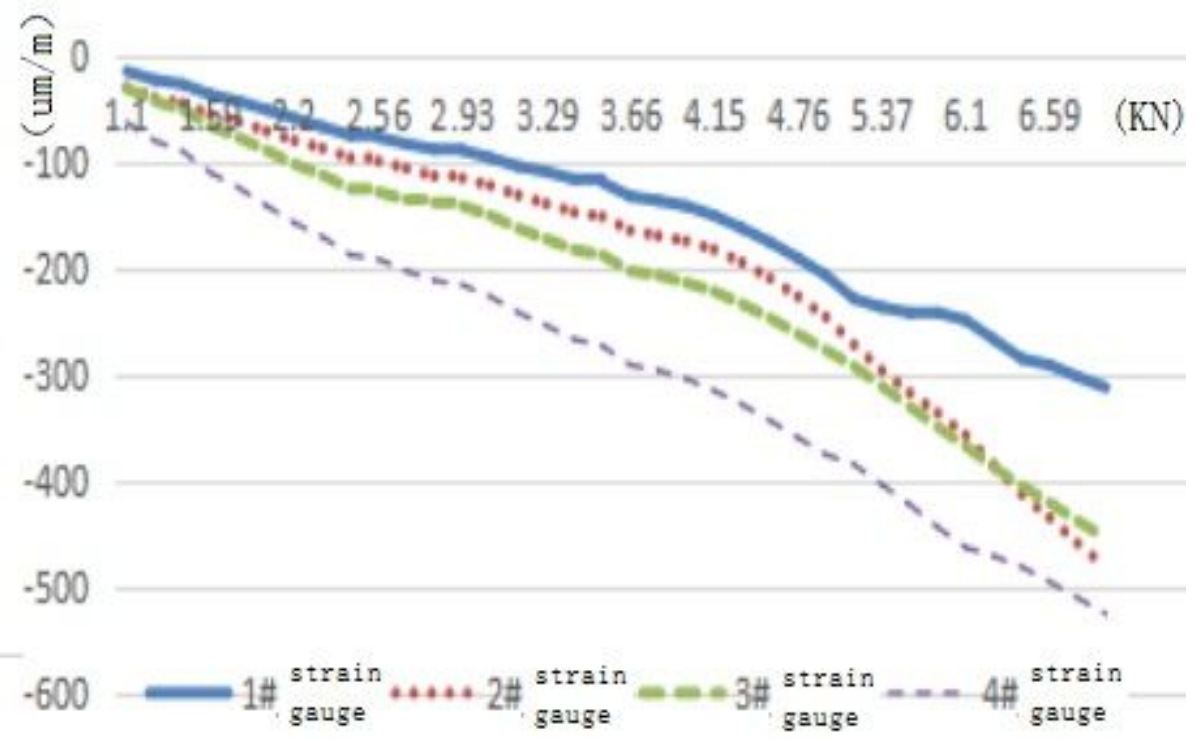

Figure 10

Load strain (upper plate) curve 1 


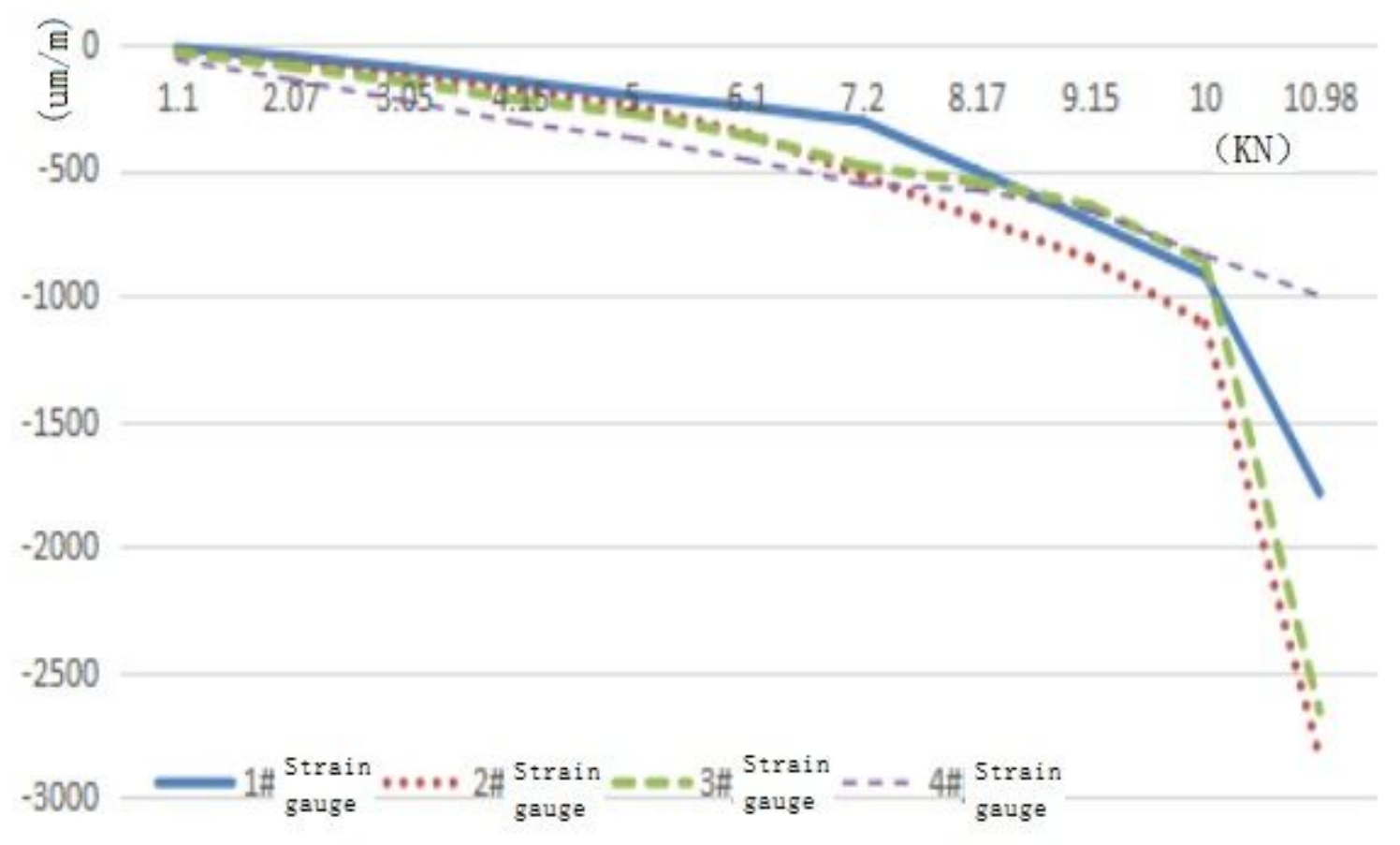

Figure 11

Load strain (upper plate) curve 2 